\title{
Predicting Self-Regulated Learning Among Scholarship Recipient Students Working on a Thesis through Forgiveness and its Dimensions: The Mediating Role of Optimism
}

\author{
Amalia Rahmandani ${ }^{1}$, Deni Sanjaya ${ }^{2}$, Dinni Asih Febriyanti ${ }^{3}$, Erin Ratna Kustanti ${ }^{4}$ \\ \{a.rahmandani@live.undip.ac.id ${ }^{1}$ \} \\ Universitas Diponegoro, Indonesia ${ }^{1,2,3,4}$
}

\begin{abstract}
This study examines the relationship between forgiveness, optimism, and selfregulated learning (SRL) among students receiving government scholarships who are working on a thesis. The role of forgiveness according to its dimensions (of self, others, and situations) is also investigated. This study involves 183 students of Universitas Diponegoro, Indonesia (age range from 20 to 24; MAge=21.43, SDAge $=0.615$ ) obtained through cluster random sampling. Using psychological scales of Forgiveness (40 items; $\alpha=0.903$ ), Optimism ( 26 items; $\alpha=0.883$ ), and Self-Regulated Learning ( 42 items; $\alpha=0.936$ ) developed by researchers, the results of all bivariate Pearson Correlations show significant positive relationships. The path analysis shows the effect of forgiveness on SRL both directly and indirectly mediated by optimism. Among the forgiveness dimensions, only the selfforgiveness has a direct effect on SRL. Optimism partially mediates the effect of each forgiveness of self and situations on SRL. The forgiveness of others has neither direct nor indirect effect through mediation of optimism on SRL. Further analysis of the prevalence and the differences of variables are also examined. These results indicate the importance of further examination of the development of programs aimed at increasing forgiveness, specifically of self and situations, in order to promote optimism and SRL among Indonesian university students.
\end{abstract}

Keywords: College Students, Forgiveness, Optimism, Self-Regulated Learning, Scholarship, Thesis

\section{Introduction}

Continuing education at university using scholarships is certainly a hope. With the stipulated regulations, scholarships are intended for students with certain characteristics and have certain implications. Previous studies at a number of universities in Indonesia have shown that scholarship acceptance has helped improve individual learning achievement [1], even better than students who did not receive scholarships [2], in addition to consumptive behaviour related to meeting academic needs [3]. Students who receive scholarships, compared to other who do not, show more mastery and performance goals [4] which are predicted by several qualities, i.e. a sense of belonging, engagement, educational attainment, and leadership efficacy [4][5][6].

However, the biggest challenge for scholarship recipients lies in having to graduate on time [7]. Studies on university students in Indonesia show that thesis accomplishment is one of the biggest inhibiting factors for study completion [8][9]. Self-regulation is considered to be one 
of the most influential factors on motivation to achieve future goals [10], including for scholarship recipients in terms of achievement motivation [11]. Self-regulation as a key process by which students direct their acquisition of academic knowledge, called self-regulated learning (SRL), is consistently associated with academic achievement at various age ranges from children, adolescents, to university students [12][13]. Self-regulated learners approach educational tasks with confidence, diligence, and resourcefulness [14]. Employing SRL strategies such as goal-setting and time-management, effort- regulation (and not 'help seeking' - which are negatively correlated), will help develop autonomous learning capacity through increasing autonomous control and learners' autonomy [15].

The increase in SRL seems to be positively influenced by optimism through the decisionmaking process [16] or engagement [17]. Optimism is a form of positive expectations for the future [18]. Seligman [19] states that optimism contains attribution-related dimensions of permanence, pervasiveness, and personalization. Among college students, optimism as a positive psychological property also accompanies adjustment and is considered the most capable of predicting academic achievement as self-reported GPA, in addition to other expectancy outcomes, i.e. health status, family life satisfaction, financial satisfaction, and general life satisfaction [20][21][22].

Based on the explanation above, there is a quite complex concern for scholarship recipients along with the demands for study completion in the midst of possible limitations, related to sense of self, interpersonal relations, or unpleasant situations beyond one's control which then affects optimism and SRL. Students may experience psychological problems that contribute to lower self-efficacy for learning, lower effort regulation (i.e., persistence) during academic work, and maladaptive academic goal orientation [23], or at least they can become an obstacle for concentrating, solving problem, making decision, and other necessary abilities for students' learning [24]. Forgiveness is a positive psychological attribute that reframes transgressions, transgressors (self, others, and situations), and sequelae of the transgression to change them from negative to neutral or positive [25]. In the academic setting among university students, forgiveness ultimately helps through avoiding procrastination and accepting responsibility [26], as well as planning goal-directed behaviour [27].

This study aims to explore the relationship between forgiveness, optimism, and selfregulated learning in Indonesian undergraduate students, specifically among students receiving government scholarships who are working on a thesis. Optimism is particularly tested whether it is a predictor that mediates the relationship between forgiveness and SRL. Further attention to the role of forgiveness of self, others, and situations is also observed.

\section{Methods}

The participants of this study are undergraduate students receiving government scholarships who are working on a thesis, which are obtained using cluster random sampling of all faculties at Universitas Diponegoro, Indonesia. A total of 183 students (male $=23.5 \%$ ) with the age range is 20 to 24 (MAge $=21.43, \mathrm{SDAge}=0.615)$ are involved in this study. Table 1 shows in more detail the characteristics of the participants.

The Forgiveness Scale $(\alpha=0.903)$ is a 40 -item Likert scale, divided into 16 favorable items and 24 unfavorable items, scored in reversed. It is developed containing dimensions of oneself $(\alpha=0.783)$, others $(\alpha=0.874)$, and situations $(\alpha=0.815)$ [28]. Respondents rate each item on the four answer choices ranged from "strongly disagree" to "strongly agree". Sample items include "I am able to calm myself back down immediately even though I feel guilty about causing a 
mess (self, favorable)," "I can see goodness in others who have hurt me (others, favorable)," and "It is difficult for me to think of good things about bad events that befell me (situations, unfavorable)".

The Thesis-Related Optimism Scale is a 26-item Likert scale $(\alpha=0.883)$ that is developed based on the dimensions of permanence, pervasiveness, and personalization [19] and contains 14 favorable items and 12 unfavorable items, scored in reverse. Students report their optimism ("I believe luck will keep on my side" [permanence, favorable], "The number of revisions that I receive is due to my inability to compose sentences" [personalization, unfavorable]). Responses are 4 options ranged from "strongly agree" to "strongly disagree".

The Thesis-Related SRL (Self-Regulated Learning) Scale is a 42-item Likert scale $(\alpha=0.936)$, developed based on the aspects of metacognition, motivation, and behaviour [14] containing 20 favorable items and 22 unfavorable items, scored in reverse. Students report their SRL ("I am able to recognize and correct the mistakes that I make during my thesis" [metacognition, favorable], "I feel that there is nothing wrong with myself when I am lazy to do my thesis" [motivation, unfavorable]). Responses are 4 options ranged from "strongly agree" to "strongly disagree".

The research procedures are carried out by applying for a research permit letters to several selected faculties taken through cluster random sampling. Researchers then obtain student data according to the specified criteria and make personal contact with class coordinators as well as potential participants. Approval from the participants to voluntarily engage in data collection, as indicated by the signing of consent forms voluntarily, is conducted to meet ethical standards.

Data analysis are performed using bivariate Pearson Correlations and the path analysis, after ensuring that the assumptions are met. Soble test is used to examine the mediating effect. T-tests, descriptive statistics, and participant categorization referring to the level of variables are also carried out.

Table 1. Demographics of participants, means and standard deviations (SD) of study variables

\begin{tabular}{|c|c|c|c|c|c|c|c|c|c|c|c|c|}
\hline \multirow{4}{*}{ Characteristics } & \multirow{4}{*}{$\begin{array}{c}\text { Frequency } \\
(\%)\end{array}$} & \multicolumn{11}{|c|}{ Variable } \\
\hline & & \multirow{2}{*}{\multicolumn{2}{|c|}{ Forgiveness }} & \multicolumn{6}{|c|}{ Forgiveness by Dimension } & \multirow{2}{*}{\multicolumn{2}{|c|}{ Optimism }} & \multirow{2}{*}{ SRL } \\
\hline & & & & \multicolumn{2}{|c|}{ Self } & \multicolumn{2}{|c|}{ Others } & \multicolumn{2}{|c|}{ Situations } & & & \\
\hline & & Mean & $\mathrm{SD}$ & Mean & SD & Mean & SD & Mean & SD & Mean & SD & \begin{tabular}{|l|l|} 
Mean & SD \\
\end{tabular} \\
\hline \multicolumn{13}{|l|}{ Sex } \\
\hline Male & $43(23.5)$ & 113.0 & 12.2 & 37.9 & 5.1 & 56.9 & 6.5 & 36.3 & 5.0 & 79.3 & 8.0 & \begin{tabular}{|l|l|}
118.9 & 15.5 \\
\end{tabular} \\
\hline Female & $140(76.5)$ & 109.7 & 15.4 & 38.1 & 6.0 & 54.4 & 7.2 & 35.4 & 6.8 & 79.6 & 8.5 & \begin{tabular}{|l|l|}
121.3 & 16.9 \\
\end{tabular} \\
\hline \multicolumn{13}{|l|}{ Field of science* } \\
\hline Natural & $93(50.8)$ & 111.7 & 13.8 & 37.8 & 5.8 & 55.6 & 6.6 & 36.4 & 6.1 & 79.5 & 7.8 & \begin{tabular}{|l|l|}
120.7 & 16.4 \\
\end{tabular} \\
\hline Social & $90(49.2)$ & 109.3 & 15.6 & 38.3 & 5.8 & 54.3 & 7.6 & 34.9 & 6.8 & 79.5 & 9.0 & \begin{tabular}{|l|l|}
120.8 & 16.7 \\
\end{tabular} \\
\hline \multicolumn{13}{|c|}{ Semester when taking a thesis } \\
\hline 7th & $79(43.2)$ & 113.5 & 12.8 & 39.5 & 5.2 & 55.7 & 6.3 & 36.8 & 5.5 & 81.1 & 7.3 & \begin{tabular}{|l|l|}
123.8 & 14.9 \\
\end{tabular} \\
\hline 8 th & $104(56.8)$ & 108.2 & 15.7 & 37.0 & 6.0 & 54.5 & 7.7 & 34.7 & 7.0 & 78.3 & 9.0 & \begin{tabular}{|l|l|}
118.4 & 17.4 \\
\end{tabular} \\
\hline \multicolumn{13}{|l|}{ Part-time worker } \\
\hline Yes & $57(31.1)$ & 114.3 & 14.9 & 39.3 & 5.8 & 55.7 & 7.6 & 37.7 & 6.1 & 80.0 & 8.7 & \begin{tabular}{|l|l|}
124.5 & 17.2 \\
\end{tabular} \\
\hline No & $126(68.9)$ & 108.8 & 14.4 & 37.5 & 5.7 & 54.7 & 6.9 & 34.7 & 6.4 & 78.9 & 8.2 & \begin{tabular}{|l|l|}
119.1 & 16.0 \\
\end{tabular} \\
\hline All participants & $183(100)$ & 110.5 & 14.7 & 38.1 & 5.8 & 54.9 & 7.1 & 35.6 & 6.5 & 79.5 & 8.4 & \begin{tabular}{|l|l|}
120.7 & 16.5 \\
\end{tabular} \\
\hline
\end{tabular}

*) Natural sciences consist of Faculty of Fisheries and Marine Sciences (n=27; 14.7\%) and Faculty of Sciences and Mathematic $(\mathrm{n}=66 ; 36.1 \%)$. Social sciences consist of Faculty of Economics and Business $(\mathrm{n}=50 ; 27.3 \%)$ and Faculty of Humanities $(\mathrm{n}=40 ; 21.9 \%)$. 


\section{Results}

Demographic data of the sample is shown in Table 1. The majority of participants are women $(76.5 \%)$, part- time workers $(68.9 \%)$, and taking thesis in their 8th semester $(56.8 \%)$. Meanwhile, the participants based on characteristic of the field of science are relatively balanced, i.e. $50.8 \%$ for natural science and $49.2 \%$ for social science. The age range of participants is from 20 to 24 (MAge $=21.43$, SDAge $=0.615$ ).

Table 1 also presents the mean and standard deviation of each variable based on the characteristics. T-test results on research variables according to sex, field of science, semester when taking a thesis, and status as a part-time worker show varied results. In the sample, sex do not distinguish all variables except forgiveness of others which is higher in males than females $(\mathrm{t}=2.008, \mathrm{p}<0.05)$. Field of science do not distinguish any variables $(\mathrm{p}>0.05)$. Semester when taking a thesis distinguishes optimism $(\mathrm{t}=2,222, \mathrm{p}<0.05), \operatorname{SRL}(\mathrm{t}=2,186, \mathrm{p}<0.05)$, forgiveness in general $(\mathrm{t}=2,418, \mathrm{p}<0.05)$, forgiveness of self $(\mathrm{t}=2,929, \mathrm{p}<0.01)$, and forgiveness of situations $(\mathrm{t}=2,259, \mathrm{p}<0.05)$, but not forgiveness of others. Whereas status as a part-time worker distinguishes $\operatorname{SRL}(\mathrm{t}=2,065, \mathrm{p}<0.05)$, forgiveness in general $(\mathrm{t}=2,363, \mathrm{p}<0.05)$, and forgiveness of others $(\mathrm{t}=2,988, \mathrm{p}<0.01)$, but not optimism, forgiveness of self and of situations.

When the hypothetical norm is used as a reference in three-group categorization, that is low $(x<\mu-\sigma)$, medium $(\mu-\sigma \leq x<\mu+\sigma)$, and high $(\mu+\sigma \leq x)$, the majority of samples have forgiveness at the medium level (74.3\%), while the rest is at a high level $(24.6 \%)$ and low (1.1\%); optimism at a high level $(59.6 \%)$, while the rest is at a medium level $(40.4 \%)$; and SRL at the medium level $(60.1 \%)$, and the rest is at the high level (38.3\%) and low (1.6\%).

Bivariate correlation examination using Pearson correlation shows that all correlations are positive and significant at $\mathrm{p}<0.001$ (Table 2). The dimension of others in forgiveness has the lowest correlation with both optimism and SRL specifically at the weak level, while each of the effect size of forgiveness of self and situations on optimism and SRL variables is the opposite and at a moderate level [29]. Forgiveness of self, others, and situations separately contributes to the variance in optimism respectively are $29.9 \%, 15 \%$, and $33.4 \%$, and to the variance in SRL respectively are $31.5 \%, 8 \%$, and $29.4 \%$. Optimism accounts for $61.7 \%$ of the variance in SRL.

Table 2. Correlation among study variables

\begin{tabular}{|l|c|c|c|c|c|}
\hline \multicolumn{1}{|c|}{ Variable } & 1 & 1. a. & 1. b. & 1. c. & 2 \\
\hline 1. Forgiveness & & & & & \\
\hline 1.a. of self & $.773^{* * *}$ & & & & \\
\hline 1.b. of others & $.775^{* * *}$ & $.384^{* * *}$ & & & \\
\hline 1.c. of situations & $.911^{* * *}$ & $.704^{* * *}$ & $.523^{* * *}$ & & \\
\hline 2. Optimism & $.592^{* * *}$ & $.547^{* * *}$ & $.387^{* * *}$ & $.578^{* * *}$ & \\
\hline 3. SRL & $.545^{* * *}$ & $.562^{* * *}$ & $.282^{* * *}$ & $.542^{* * *}$ & $.785^{* * *}$ \\
\hline$* * *) \mathrm{p}<0.001$
\end{tabular}

The first model of path analysis is made to examine the mediating effect of optimism on the relationship between forgiveness in general and SRL. Goodness of fit for the model is obtained, with $\chi 2=-0.00 ; p=1.00000$; and RMSEA $=0,000$. Figure 1 shows that forgiveness has a direct effect on optimism $(b=0.338, S E=0.034, \beta=0.59, p<0.001)$ and $S R L(b=0.138$, $\mathrm{SE}=0.063, \beta=0.12, \mathrm{p}<0.05)$. Optimism has a direct effect on $\mathrm{SRL}(\mathrm{b}=1,401, \mathrm{SE}=0.110, \beta=0.71$, $\mathrm{p}<0.001$ ). Optimism partially mediates the relationship between forgiveness and SRL (Sobel's test on the indirect pathway is significant, with $\mathrm{z}=7,837, \mathrm{p}<0.001)$. Forgiveness accounts for 
$35 \%$ of the variance in optimism and $29.7 \%$ of the variance in SRL. Both predictors all together explain $62.7 \%$ of the variance of SRL.

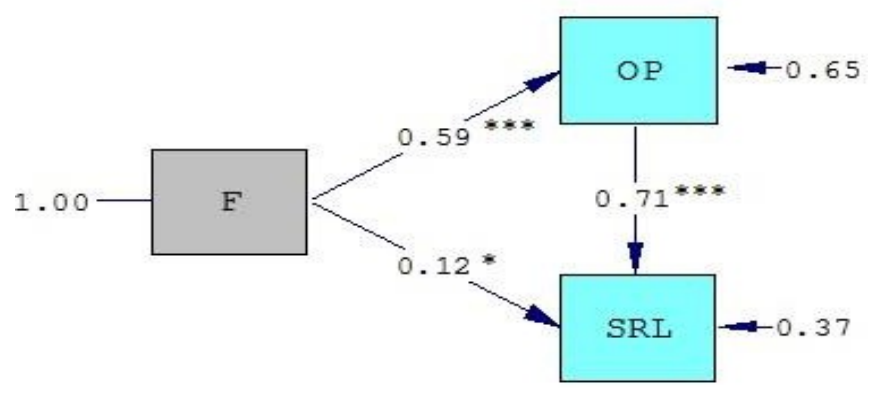

Fig. 1. The mediation model of optimism in the relationship between forgiveness and self-regulated learning. All the coefficients in figure are standardized. $\mathrm{F}=$ forgiveness, OP $=$ optimism, SRL $=$ selfregulated learning, $* \mathrm{p}<0.05, * * * \mathrm{p}<0.001$.

The second model of path analysis is made to examine the mediating effect of optimism on the relationship between forgiveness of self, others and situations, with SRL. Goodness of fit for the model is obtained, with $\chi 2=-0.00 ; p=1.00000$; and RMSEA $=0,000$. Figure 2 shows that the forgiveness of self has a direct effect on optimism $(b=0.398, S E=0.120, \beta=0.27, p<0.01)$ and SRL $(b=0.483, S E=0.183, \beta=0.17, p<0.01)$. Forgiveness of others has no direct effect both on optimism $(b=0.130, \mathrm{SE}=0.081, \beta=0.11, \mathrm{~ns})$ and $\mathrm{SRL}(\mathrm{b}=-0.198, \mathrm{SE}=0.121, \beta=-0.09$, ns). Forgiveness of situations has a direct effect on optimism $(b=0.426, S E=0.116, \beta=0.33, p<0.001)$ but not SRL $(b=0.183, S E=0.179, \beta=0.07, n s)$. Optimism has a direct effect on SRL $(b=1,346$, $\mathrm{SE}=0.111, \beta=0.68, \mathrm{p}<0.001)$. Optimism partially mediates the relationship between forgiveness of self $(\mathrm{z}=3,199, \mathrm{p}<0.01)$ and situations $(\mathrm{z}=3,515, \mathrm{p}<0.001)$, except forgiveness of others $(\mathrm{z}=1,591, \mathrm{~ns})$, with SRL. These three dimensions of forgiveness together contribute to $38.2 \%$ of the variance in optimism and $35.8 \%$ of the variance in SRL. All predictors together explain $64.7 \%$ of the variance of SRL.

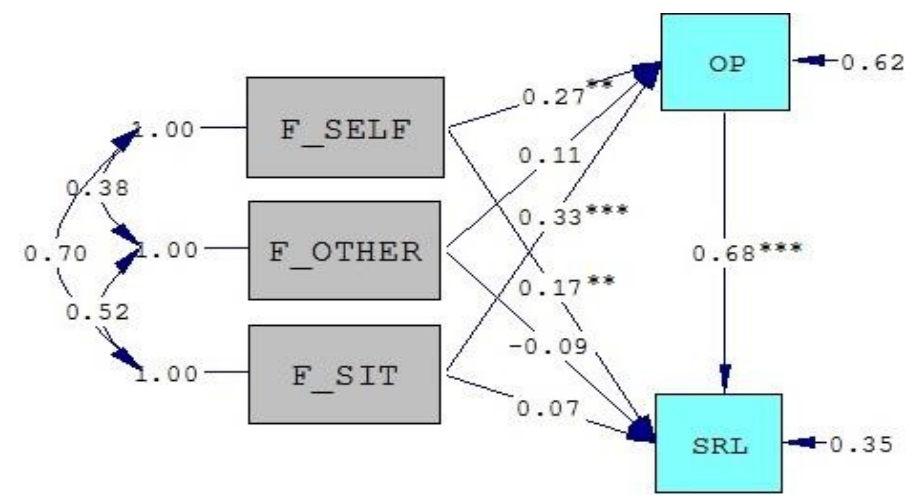

Fig. 2. The mediation model of optimism in the relationship between forgiveness of self, others, and situations, with self-regulated learning. All the coefficients in figure are standardized. F_SELF = forgiveness of self, F_OTHER $=$ forgiveness of others, F_SIT $=$ forgiveness of situations, $\mathrm{OP}=$ optimism, $\mathrm{SRL}=$ self-regulated learning, ${ }^{* *} \mathrm{p}<0.01,{ }^{*} * \mathrm{p}<0.001$ 
The third model of path analysis is made to examine the mediating effect of optimism on the relationship between forgiveness of others, without the other both dimensions of forgiveness, and SRL. Goodness of fit for the model is obtained, with $\chi 2=-0.00 ; p=1.00000$; and RMSEA $=0,000$. Figure 3 shows that forgiveness of others, independently without other dimensions of forgiveness, has a direct effect on optimism $(b=0.456, S E=0.081, \beta=0.39$, $\mathrm{p}<0.001)$, but not SRL $(\mathrm{b}=-0.059$, $\mathrm{SE}=0.115, \beta=-0.03$, ns). Optimism has a direct effect on $\mathrm{SRL}$ $(b=1,564, S E=0.098, \beta=0.80, p<0.001)$. This model explains that optimism partially mediates the relationship between forgiveness of others and SRL $(\mathrm{z}=5.334, \mathrm{p}<0.001)$. Lastly, both predictors all together explain $61.8 \%$ of the variance of SRL.

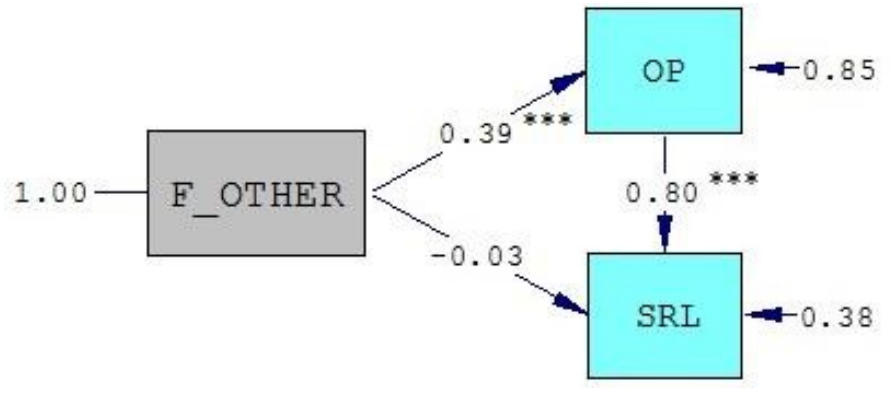

Fig. 3. The mediation model of optimism in the relationship between forgiveness of others and selfregulated learning. All the coefficients in figure are standardized. F OTHER = forgiveness of others, $\mathrm{OP}=$ optimism, $\mathrm{SRL}=$ self-regulated learning, ${ }^{* * *} \mathrm{p}<0.001$.

\section{Discussion}

The results of this study indicate that forgiveness is positively related to optimism and SRL. Furthermore, optimism mediates the relationship between forgiveness and SRL. Students receiving scholarship tend to be better than non-receiver in terms of academic (and social) engagement, educational attainment, and leadership efficacy which is a process-oriented and change-directed phenomenon [5][6]. These things seem to be supported by the presence of a number of attributes that may be predicted by forgiveness, namely positive self-evaluation [30], self-control [31][32], self-efficacy or mastery over environmental demands or sense of control [33][34]. These attributes then predict optimism [35][36][37[[38] and SRL [39][40[41][42][43]. Furthermore, optimism predicts self-regulated learning, two of them are through engagement [17] and the decision-making process [16]. The prevalence's of forgiveness, optimism, and SRL variables in the subjects in this study are mostly in the medium $(40.4 \%$ to $74.3 \%)$ and high $(24.6 \%$ to $59.6 \%)$ categories. Only $1.1 \%$ to $1.6 \%$ are in the low category.

The explanation above regarding the sense of self may support the results of why only selfforgiveness has a direct effect on SRL and indirectly through optimism, which indicates the magnitude of the effect of self-forgiveness on higher urge in academic achievement among university students, such as in term of avoiding procrastination and accepting responsibility [26], as well as in terms of goal-directed behaviour [27]. Self-Forgiveness itself involves reducing negative and increasing positive thoughts, emotions, motivations and behaviors regarding oneself [44]. Slightly different, forgiveness of situations has no direct effect on SRL, except through optimism. Forgiveness of situations may be associated with a 'softening' 
appraisal to the situation so that it can be considered a less threatening stressor thereby discourages and reduces coping-based behaviour [45][46], in this case SRL (which is supported by the additional results that show that SRL in those who are part-time workers is significantly higher than in those who are not); on the contrary, increasing optimism [47].

Forgiveness of others has the lowest correlation with optimism and SRL. Furthermore, along with other dimensions of forgiveness, the forgiveness of others has no direct effect on SRL and on optimism. The relationship with SRL is obtained indirectly through optimism, especially when the examination is not carried out with the other dimensions of forgiveness as predictors. In contrast to the explanation of the effects of forgiveness of self and situations, then forgiveness of others globally includes other-focused concerns or is more directed towards interpersonal functioning and gaining a sense of social harmony [48][49]. It is considered less needed (compared to one's self-focused concern) to boost one's optimism and SRL; on the contrary, the forgiveness of others in collectivistic cultures includes societally enforced ideals or strong norms to maintain social harmony [50][51] although they are not ready to reconcile [52] and even may induce self-sacrifice [53].

\section{Conclusion}

This study adds to the discourse on how the dynamics of forgiveness, both in general and regarding self-lack, offense by others, or events beyond one's control can contribute to educational settings. Further studies are expected to consider different target samples, for example those with a history of childhood adversities, or those with internet usage problem, or simply to non-problematic possible students or students with a lower level of education; in addition to further examination of the development of programs aimed at increasing forgiveness, specifically of self and situations, in order to promote optimism and SRL among Indonesian university students.

\section{References}

[1] I. W. B. Arsana, J. Progr. Stud. Pendidik. Ekon., 6, 1, (2016).

[2] H. Takriyuddin, Z. Mukmin, and M. Yunus, J. Ilm. Mhs. Pendidik. Kewarganegaraan Unsyiah, 1, $1,(2016)$

[3] A. P. Wulandari, Putri, and Heri Yanto, J. Econ. Educ., 5, 2, (2016).

[4] S. Won, C. A. Wolters, and S. A. Mueller, J. Exp. Educ., 86, 3, (2018).

[5] A. Boatman and B. T. Long, Res. High. Educ., 57, 6, (2016).

[6] S. Hu, J. Higher Educ., 82, 5, (2011).

[7] Bidikmisi, (2019). [Online]. Available: https://bidikmisi.belmawa.ristekdikti.go.id/petun juk/index. [Accessed: 01-Sep-2020].

[8] H. Ihsan and A. Zaki, Sci. Pinisi, 1, 1, (2015).

[9] E. N. Aslinawati and S. U. Mintarti, J. Pendidik. Ekon., 10, 1, (2017).

[10] R. B. Miller and S. J. Brickman, Educ. Psychol. Rev., (2004).

[11] A. H. Nurillah and A. Chusairi, Insa. J. Psikol. dan Kesehat. Ment., 3, 2, (2020).

[12] A. L. Dent and A. C. Koenka, Educ. Psychol. Rev., 28, 3, (2015).

[13] S. Xiao, K. Yao, and T. Wang, SHS Web Conf., 60, 01003, (2019).

[14] B. J. Zimmerman, Educ. Psychol., 25, 1, (1990).

[15] Z. Papamitsiou and A. A. Economides, Br. J. Educ. Technol., 50, 6, (2019).

[16] E. Khodarahmi and N. Zarrinabadi, Curr. Psychol., 35, 4, (2016).

[17] S. Nurttila, E. Ketonen, and K. Lonka, Procedia-Soc. Behav. Sci., 171, 1017-1026, (2015). 
[18] M. F. Scheier, C. S. Carver, and M. W. Bridges, J. Pers. Soc. Psychol., 67, 1063-1078, (1994).

[19] M. E. P. Seligman, Learned Optimism: How to change your mind and your life, (2006).

[20] E. C. Chang, M. R. Bodem, L. J. Sanna, and C. G. Fabian, J. Posit. Psychol., 6, 5, (2011).

[21] D. B. Feldman, O. B. Davidson, and M. Margalit, J. Happiness Stud., 16, 3, (2015).

[22] T. Gordeeva, K. Sheldon, and O. Sychev, Eur. J. Psychol. Educ., 35, 1, (2020).

[23] Ness BM, Middleton MJ, and Hildebrandt MJ., J. Am. Coll. Heal., 63, 7, (2015).

[24] M. Yazdani, S. Rezaei, and S. Pahlavanzadeh, Iran. J. Nurs. Midwifery Res., 15, 4, (2010).

[25] L. Y. Thompson et al., J. Pers., 73, 2, (2005).

[26] L. Martinčeková and R. D. Enright, Curr. Psychol., no. Ferrari 1994, (2018).

[27] A. Pierro, G. Pica, A. M. Giannini, E. Tory Higgins, and A. W. Kruglanski, PLoS One, 13, 3, (2018).

[28] L. Y. Thompson et al., J. Pers., 73, 2, (2005).

[29] H. Akoglu, Turkish J. Emerg. Med., 18, 3, (2018).

[30] X. Xie, X. Tang, H. Rapp, D. Tong, and P. Wang, Comput. Human Behav., 109, no. October 2019 (2020).

[31] J. L. Burnette, E. K. Davisson, E. J. Finkel, D.R. Van Tongeren, C. M. Hui, and R. H. Hoyle, Soc. Psychol. Personal. Sci., 5, 4, (2014).

[32] F. I. García-vázquez, A. A. Valdés-cuervo, B. Martínez-ferrer, and L. G. Parra-pérez, Front. Psychol., 10, January, (2020).

[33] C. Gençoğlu, E. Şahin, and N. Topkaya, Educ. Sci. Theory Pract., 18, 3, (2018).

[34] P. L. Hill and M. Allemand, J. Res. Pers., 44, 2, (2010).

[35] Y. M. C. Meevissen, M. L. Peters, and H. J. E. M. Alberts, J. Behav. Ther. Exp. Psychiatry, 42, 3, (2011).

[36] C. S. Carver, Pers. Individ. Dif., 66, 24-26, (2014).

[37] D. B. Feldman and M. Kubota, Learn. Individ. Differ., 37, 210-216, (2015).

[38] D. Monzani, P. Steca, and A. Greco, J. Adolesc., 37, 2, (2014).

[39] D. M. McInerney, The Motivational Roles of Cultural Differences and Cultural Identity in SelfRegulated Learning, New York, NY: Lawrence Erlbaum Associates, (2008).

[40] S. Cassidy, Stud. High. Educ., 36, 8, (2011).

[41] Y. Zhu, W. Au, and G. Yates, Internet High. Educ., 30, (2016).

[42] K. R. Jung, A. Q. Zhou, and R. M. Lee, Learn. Individ. Differ., 60, November 2016, (2017).

[43] Ş. Şen, A. Y1lmaz, and Ö. Geban, Probl. Educ. 21st Century, 66, (2015).

[44] D. E. Davis et al., J. Couns. Psychol., 62, 2, (2015).

[45] A. Chalabaev, B. Major, P. Sarrazin, and F. Cury, Motiv. Emot., 36, 2, (2012).

[46] P. Sheeran, P. R. Harris, and T. Epton, Psychol. Bull., 140, 2, (2014).

[47] A. Denovan and A. Macaskill, J. Happiness Stud., 18, 2, (2017).

[48] R. D. Enright, S. Freedman, and J. Rique, The psychology of interpersonal forgiveness, Madison, WI: University of Wisconsin Press, (1998).

[49] M. E. McCullough and V. O. Witvliet, The psychology of forgiveness, London, UK: Oxford University Press, (2002).

[50] S. J. Sandage and I. Williamson, Forgiveness in cultural context, New York, NY: Routledge, (2005).

[51] J. C. Karremans et al., Soc. Psychol. Personal. Sci., 2, 5, (2011).

[52] J. N. Hook, E. L. Worthington Jr, S. O. Utsey, D. E. Davis, and J. L. Burnette, Couns. Values, 57, April, (2012).

[53] S. Akhtar, Good Stuff: Courage, Resilience, Gratitude, Generosity, Forgiveness, and Sacrifice. Lanham, Maryland: Jason Aronson, (2013). 